\title{
Progressive non-fluent aphasia
}

INSERM

\section{Source}

INSERM. (1999). Orphanet: an online rare disease and orphan drug data base.

Progressive non-fluent aphasia. ORPHA:100070

Progressive non-fluent aphasia (PNFA) is a form of frontotemporal dementia (FTD; see this term), characterized by agrammatism, laborious speech, alexia, and agraphia, frequently accompanied by apraxia of speech (AOS). Language comprehension is relatively preserved. 